\title{
Learning-facilitated long-term depression and long-term potentiation at mossy fiber-CA3 synapses requires activation of $\beta$-adrenergic receptors
}

\author{
Hardy Hagena ${ }^{1,2}$ and Denise Manahan-Vaughan ${ }^{1,2 *}$ \\ 1 Medical Faculty, Department of Neurophysiology, Ruhr University Bochum, Bochum, Germany \\ 2 International Graduate School for Neuroscience, Ruhr University Bochum, Bochum, Germany
}

Edited by:

Alan Carleton, University of Geneva, Switzerland

\section{Reviewed by:}

Hao Zhang, University of Oxford, UK Brian E. Derrick, The University of Texas, USA

Bruce McNaughton, The University of Lethbridge, Canada

${ }^{*}$ Correspondence:

Denise Manahan-Vaughan, Medical Faculty, Department of

Neurophysiology, Ruhr University

Bochum, MA 4/150,

Universitaetsstr. 150, 44780

Bochum, Germany.

e-mail:dmv-igsn@rub.de
Learning-facilitated plasticity refers to hippocampal synaptic plasticity that is facilitated by novel spatial learning events. Both long-term potentiation (LTP) and long-term depression (LTD) are facilitated by novel hippocampus-dependent learning. This has important ramifications for our understanding of how the hippocampus encodes memory. One structure that is rarely studied in vivo, but is believed to be crucially important for working and long-term memory processing is the hippocampal CA3 region. Whereas learning-facilitated plasticity has been described in this structure, the mechanisms underlying this phenomenon have not been explored. The noradrenergic system plays an important role in arousal and qualification of new information as salient. It regulates synaptic plasticity in the dentate gyrus and CA1, but nothing is known about the regulation by the noradrenergic system of synaptic plasticity in the CA3 region. We explored whether $\beta$-adrenergic receptors contribute to learning-facilitated plasticity at mossy fiber (mf)-CA3 synapses of behaving rats. We found that receptor antagonism had no effect on basal synaptic transmission, short-term potentiation (STP), short-term depression, LTP, or LTD, that were electrically induced by patterned afferent stimulation. We found, however, that both learning-facilitated LTP and LTD were prevented by antagonism of $\beta$-adrenergic receptors, whereas the agonist isoproterenol facilitated STP into LTP. Thus, learning-facilitated and electrically-induced plasticity may not share the same prerequisites. These results support that the $\mathrm{mf}$ synapse engages in a distinct aspect of encoding of spatial information that involves both LTP and LTD. Furthermore, changes in arousal that are coupled to new learning are associated with activation of hippocampal $\beta$-adrenergic receptors that in turn comprise a key element in this type of information acquisition and processing by the CA3 region.

Keywords: CA3, noradrenaline, novelty exploration, spatial learning, beta-adrenergic receptor

\section{INTRODUCTION}

Bidirectional changes of synaptic plasticity, expressed in the form of LTP and LTD, are involved in the encoding and storage of information in the hippocampus (Bear and Malenka, 1994; Bear and Abraham, 1996; Manahan-Vaughan and Braunewell, 1999; Kemp and Manahan-Vaughan, 2007). More recently, it has become apparent that the coupling of spatial learning experience with the induction of short-lasting forms of synaptic plasticity results in persistent long-term potentiation (LTP) or long-term depression (LTD), depending on the stimulation and learning conditions used (Kemp and Manahan-Vaughan, 2007). Strikingly, exploration of novel space leads to facilitation of LTP at all synapses studied to date (perforant path-dentate gyrus, Schaffer collateral-CA1, mossy fiber (mf)-CA3, commissuralassociational-CA3) (Kemp and Manahan-Vaughan, 2004, 2008a; Hagena and Manahan-Vaughan, 2011). LTD, however, exhibits a more discriminatory relationship with spatial learning. Whereas
LTD at perforant path-dentate gyrus synapses is facilitated by exploration of spatially arranged large novel objects that serve as orientational landmarks, at Schaffer collateral-CA1 synapses LTD is only facilitated when the spatial environment contains small, less prominent cues, that can even be partially concealed and thus cannot be used as orientational cues (Manahan-Vaughan and Braunewell, 1999; Kemp and Manahan-Vaughan, 2004, 2008a). At CA3 synapses, even more functional discrimination is evident: LTP at selected $\mathrm{mf}$ synapses is facilitated by novel landmarks, whereas LTD at commissural-associational fibers is facilitated by small spatial cues (Hagena and Manahan-Vaughan, 2011). These changes, that are referred to as learning-facilitated plasticity, are not simply driven by exploratory behavior: re-exposure to the spatial information days after the first exposure does not facilitate plasticity, and behavioral analysis has shown that learning occurred during exploration (Manahan-Vaughan and Braunewell, 1999; Kemp and Manahan-Vaughan, 2007; Hagena 
and Manahan-Vaughan, 2011; Popkirov and Manahan-Vaughan, 2011). The behavioral state of the animal is also likely to play an important role. One key factor in enabling the animal to distinguish salient from irrelevant information and to effectively store this information both synaptically and in the form of a memory engram, is the activity of neuromodulators (Devauges and Sara, 1991; Ikegaya et al., 1997; SwansonPark et al., 1999; Straube and Frey, 2003; Bouret and Sara, 2005).

Of the extensive family of neuromodulators, the noradrenergic system is of particular interest. Adrenergic receptors are abundant throughout the whole brain and are found in equal distribution in the hippocampus, which receives its major adrenergic input from the locus coeruleus (Loy et al., 1980). Studies suggest a role of $\beta$-adrenergic receptors in network activity in area CA3 (Jurgens et al., 2005). Furthermore, the noradrenergic system is involved in multiple mechanisms underlying the formation of memory, such as reconsolidation (Roullet and Sara, 1998) and memory retrieval (Devauges and Sara, 1991; Murchison et al., 2004). It has also been shown that the noradrenergic system is important for novelty exploration (Delini-Stula et al., 1984) since an increase in noradrenergic activity, characterized by an increase in firing of the locus coeruleus is observed during novelty detection (Sara et al., 1994; Kitchigina et al., 1997). Activation of the $\beta$-adrenergic system also activates signaling cascades leading to the priming of metaplastic mechanisms in CA1 (Tenorio et al., 2010), and the $\beta$-adrenergic receptor subtype $\beta 1$ modulates LTP through activation of MAP kinase (ERK) (Winder et al., 1999).

We have shown that activation of $\beta$-adrenergic receptors play a crucial role in NMDA receptor-dependent learning-facilitated long-term plasticity in the CA1 region of freely behaving adult rats (Kemp and Manahan-Vaughan, 2008b; Lemon et al., 2009; Popkirov and Manahan-Vaughan, 2011). The CA3 mf synapse is likely to play a distinct role in information processing, due to its very characteristic mechanistic properties of synaptic plasticity (Contractor et al., 2001; Bortolotto et al., 2003; Hagena and Manahan-Vaughan, 2010). Based on behavioral studies, and work conducted either on place cell characteristics in vivo or synaptic plasticity in vitro, a role for $\mathrm{mf}$ synapses in pattern separation, pattern completion, and in forming heteroassociative connections between discrete memory patterns has been proposed (McNaughton and Morris, 1987; Treves and Rolls, 1992; O'Reilly and McClelland, 1994; Blum and Abbott, 1996; Lee et al., 2004). Little is known about the relationship between $\mathrm{mf}$ synaptic plasticity and spatial learning in intact animals, and the neuromodulators that regulate this relationship. The question remains unanswered as to whether persistent $(>24 \mathrm{~h}$ ) synaptic plasticity at $\mathrm{mf}$ synapses, that is distinct from CA1 and dentate gyrus plasticity both in its locus of expression and its induction mechanisms (Jaffe and Johnston, 1990; Zalutsky and Nicoll, 1990; Johnston et al., 1992; Bliss and Collingridge, 1993; Bear and Malenka, 1994; Hagena and Manahan-Vaughan, 2010), is also subject to regulation by neuromodulators such as noradrenalin. In the present study, we therefore, examined to what extent $\beta$-adrenergic receptors contribute to learning-facilitated plasticity in $\mathrm{mf}-\mathrm{CA} 3$ synapses in freely behaving adult rats.

\section{MATERIALS AND METHODS}

The present study was carried out in accordance with the European Communities Council Directive of September 22nd, 2010 (2010/63/EU) for care of laboratory animals and after approval of the local government ethics committee. All efforts were made to minimize the number of animals used.

\section{ELECTROPHYSIOLOGY}

Seven-to eight-week old male Wistar rats (Charles River, Germany) were anaesthetized (Pentobarbital, $52 \mathrm{mg} / \mathrm{kg}$, intraperitoneally) and underwent chronic implantation of hippocampal electrodes and a guide cannula, as described previously (Hagena and Manahan-Vaughan, 2010). Briefly, a monopolar recording electrode was implanted in CA3 stratum lucidum (AP: -3.2; ML: 2.2) and a bipolar stimulation electrode in the mf pathway (AP: -3.5 ; ML: -2.0 ). To enable injections, a guide-cannula was placed in the ipsilateral cerebral ventricle, as described previously (Manahan-Vaughan, 1997). Experiments were commenced 7-10 days after surgery. During all experiments the animals could move freely in the recording chamber $(40 \times 40 \times 50 \mathrm{~cm})$ and had free access to food and water. To allow the animals to acclimatize they were transferred to the experiment room the day before the experiment took place.

Before experiments were begun, animals were stringently assessed to confirm that recordings were obtained from mf-CA3 synapses. The $\mathrm{mf}$ synapse is highly sensitive to agonist activation of group II metabotropic glutamate receptors (mGluRs) by $\left(2 \mathrm{~S}, 2^{\prime} \mathrm{R}, 3^{\prime} \mathrm{R}\right)-2-\left(2^{\prime}, 3^{\prime}\right.$-dicarboxycyclopropyl)glycine (DCG-IV) that selectively inhibits $\mathrm{mf}$ but not associational-commissural excitatory postsynaptic potentials (EPSPs) (Kamiya and Ozawa, 1998; Yeckel et al., 1999; Goussakov et al., 2000, Figure 2A). Animals were excluded from the study when the field excitatory postsynaptic potential (fEPSP) responses evoked in the stratum lucidum failed to show strong sensitivity (i.e., a reduction of test-pulse-evoked responses by $60 \%$ or greater) to DCG-IV, $1 \mathrm{~h}$ after DCG-IV application. To avoid an influence on fEPSPs mediated by DCG-IV on subsequent experiments, it was ensured that potentials had fully recovered before those experiments were performed. In addition, routine studies were conducted to verify that $\mathrm{N}$-methyl-D-aspartate (NMDA)-receptor dependent LTP was not evident in these synapses (Hagena and ManahanVaughan, 2010). Here, 30 min before tetanization to induce LTP, the NMDA receptor antagonist, D-AP5 was applied to examine whether LTP was influenced by the antagonist (Figure 2B). Only animals whose LTP was unaffected were included in the current study. Postmortem histological analysis of the electrode localizations was also conducted (Bock, 1989; Manahan-Vaughan et al., 1998).

For recordings from freely behaving animals, the head stage was connected to an amplifier and stimulator via a flexible cable with a swivel connector. Recordings were analyzed and stored on computer and the EEG was monitored throughout experiments to observe if animals had epileptic seizures as a result of patterned afferent stimulation. If this was the case the affected animals were excluded from the study.

To evoke fEPSPs a biphasic pulse was given with half-wave duration of $0.2 \mathrm{~ms}$. For recordings, the stimulation intensity 
was set to produce a fEPSP, which was $40 \%$ of the maximal obtainable. The intensity was found on the basis of an inputoutput curve (maximal stimulation $900 \mu \mathrm{A}$ ). Each recording consisted of an average of five consecutive pulses at $0.025 \mathrm{~Hz}$. To ensure stability of recordings, all animals were first tested in a baseline experiment where test-pulse stimulation was applied over the same time-period as subsequent plasticity experiments.

To induce LTD, low frequency stimulation (LFS) consisting of 900 pulses at $1 \mathrm{~Hz}$, was given with a stimulus intensity that yielded potentials, which were $70 \%$ of the maximal fEPSP observed during the input-output curve analysis. Sub-threshold LFS (sLFS, 600 pulses), meaning patterned stimulation that was inadequate for the induction of persistent LTD, was applied to induce short-term depression (STD) $(<2 \mathrm{~h}$ ). LTP was induced by high-frequency stimulation (HFS) of afferent fibers. This comprised of four bursts of 100 pulses at $100 \mathrm{~Hz}$, with a 5 min interburst interval. For short-term potentiation (STP, $<2 \mathrm{~h}$ ), 2 bursts of 100 pulses at $100 \mathrm{~Hz}$ (sHFS) were used. Animals participating in LTP experiments had a minimum age of 12 weeks as we observed that application of HFS in younger animals causes epileptiform seizures.

\section{SPATIAL EXPLORATION}

In the experiments concerning learning-induced plasticity, a holeboard $(39.8 \times 39.8 \mathrm{~cm})$ was inserted into the recording chamber immediately after the first hour of recording, and left there whilst patterned stimulation (sLFS, sHFS) was applied. Animals were allowed to explore the holeboard for $10 \mathrm{~min}$ before it was removed. The holeboard had four holes $(5.5 \mathrm{~cm}$ in diameter and $5 \mathrm{~cm}$ deep) in each corner. The holes were empty in LTP (sHFS) experiments (empty holeboard). For LTD (sLFS) experiments, three large objects $(5-10 \mathrm{~cm}$ in diameter and $5-12 \mathrm{~cm}$ in height) were inserted directly into the recording chamber for the duration of sLFS. To ensure maximal familiarization with the recording chamber and external environment, the individual rats were assigned a particular recording chamber where all experiments with the animal were carried out. Re-exposure to the holeboard or to the large objects (landmarks) took place at least 7 days after first exposure. The second re-exposure to the holeboard took place a further minimum of 7 days after first re-exposure. During re-exposure experiments the same holeboard was used, and in the case of LTD (sLFS) experiments, the landmarks were always placed in the same holeboard holes as used during novel exposure.

\section{DRUGS}

The $\beta$-adrenergic receptor antagonist propranolol or the agonist isoproterenol (Biotrend, Germany) were dissolved in isotonic saline $(0.9 \% \mathrm{NaCl})$ solution and injected in a $5 \mu \mathrm{l}$ volume. Throughout plasticity experiments, the drug amount used was 2 or $4 \mu \mathrm{g}$ for propranolol and $20 \mu \mathrm{g}$ for isoproterenol. The dosage was chosen on the basis of baseline experiments, where we found that basal synaptic transmission was unaffected. In control experiments a vehicle injection of $5 \mu \mathrm{l}$ saline was given. The group II mGlu receptor agonist, DCG-IV (Tocris Cookson, Bristol, UK) was dissolved in isotonic saline $(0.9 \%$
$\mathrm{NaCl}$ ) solution. The amount of DCG-IV that was used (20 ng) was chosen because it has no effect on evoked responses in the dentate gyrus (Klausnitzer and Manahan-Vaughan, 2008). The NMDA-receptor antagonist D-AP5 D-(-)-2-amino-5phosphopentanoic acid (Tocris-Cookson Ltd., Bristol, UK) was first dissolved in $5 \mu \mathrm{l}$ of $1 \mathrm{~N}$ sodium hydroxide solution $(\mathrm{NaOH})$, then $0.9 \%$ sodium chloride $(\mathrm{NaCl})$ as added to make up a solution of $100 \mu \mathrm{l}$ volume. All injections were given via the intracerebral ventricle (i.c.v.), specifically via the ipsilateral ventricle by means of the implanted cannula.

\section{DATA ANALYSIS}

We used the initial slope of the fEPSP, which reflects the synaptic strength. For each time-point, five consecutively evoked responses at $40 \mathrm{~s}$ intervals were averaged. The first $30 \mathrm{~min}$ of recording (six time-points) served as baseline, and the results were expressed as the mean percentage \pm the standard error of the mean (SEM) of the average baseline value. Recordings were made every $5 \mathrm{~min}$ until $30 \mathrm{~min}$ after LFS/HFS and then every $15 \mathrm{~min}$ until $4 \mathrm{~h}$ had elapsed. The following day an additional $1 \mathrm{~h}$ of recordings were obtained. For analysis of difference between groups a TwoWay ANOVA was applied. The levels of significance were set at $p<0.05$.

\section{RESULTS}

\section{BASAL SYNAPTIC TRANSMISSION IS NOT INFLUENCED BY ANTAGONISM OF $\beta$-ADRENERGIC RECEPTORS}

First, we evaluated the effect of the $\beta$-adrenergic antagonist, propranolol, on basal synaptic transmission. It has been shown that a dose of $2 \mu \mathrm{g}$ (applied to the lateral cerebral ventricle, i.c.v) does not significantly alter synaptic transmission evoked at Schaffer collateral-pyramidal cell synapses in the CA1 region (Kemp and Manahan-Vaughan, 2008b). Thus, we assessed both this dose and a dose of $4 \mu \mathrm{g}$. Basal synaptic transmission in mf synapses was evoked by test-pulse stimulation at $0.025 \mathrm{~Hz}$. Responses were stable in vehicle-injected controls over the ca. $24 \mathrm{~h}$ monitoring period. Treatment with propranolol $(2 \mu \mathrm{g}$ or $4 \mu \mathrm{g}$ i.c.v.) had no influence on the stability of basal synaptic transmission at mf-CA3 synapses (Figure 1). For the $2 \mu \mathrm{g}$ dose: [ANOVA, $F_{(1,244)}=0.06 ; p=0.81 ; n=8$ ]. For the $4 \mu \mathrm{g}$ dose: [ANOVA, $\left.F_{(1,398)}=5.82 ; p=0.16 ; n=8\right]$.

\section{ELECTRICALLY INDUCED SYNAPTIC POTENTIATION IS NOT ALTERED BY $\beta$-ADRENERGIC RECEPTOR ACTIVITY AT MOSSY FIBER-CA3 SYNAPSES}

We then explored whether synaptic potentiation that endures for ca. $2 \mathrm{~h}$ was affected by antagonism of $\beta$-adrenergic receptors. In vehicle-treated animals, high frequency stimulation that was sub-threshold for inducing persistent LTP (sHFS: 2 bursts of 100 pulses at $100 \mathrm{~Hz}$ ) elicited STP that endured for ca. $2 \mathrm{~h}$ (Figure 2). In the presence of propranolol ( $2 \mu$ g, i.c.v.), electrically-induced STP did not differ significantly from responses evoked in the presence of vehicle at the mf-CA3 synapse [ANOVA, $F_{(1,262)}=$ 3.53; $p=0.06 ; n=7$ in both groups] (Figure 2). Application of the group II mGlu receptor agonist, DCG-IV, after the recordings, selectively blocked $\mathrm{mf}$ responses by $40 \%$ or greater (Figure 2A). Synaptic plasticity evoked at mf-CA3 synapses is 


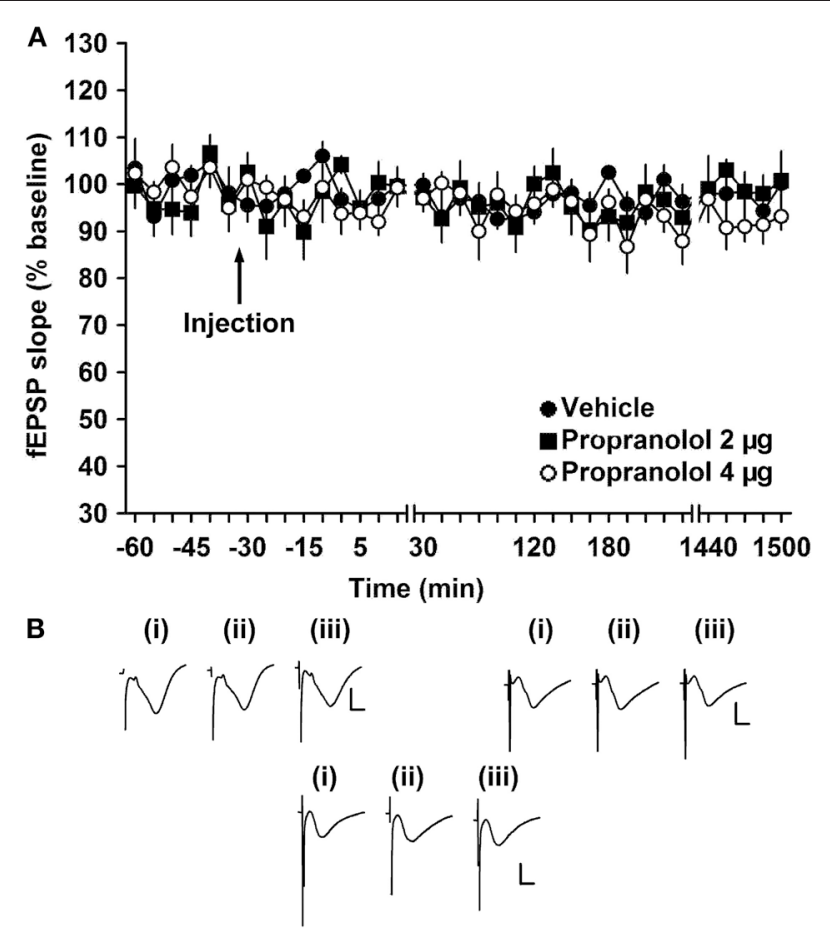

FIGURE 1 | $\beta$-adrenergic receptor antagonism does not alter basal synaptic transmission. (A) Vehicle-injected animals exhibit stable basal synaptic transmission at mossy fiber-CA3 synapses for the duration of the experiment. Application of the $\beta$-adrenergic receptor antagonist, propranolol (2 or $4 \mu \mathrm{g}$ ) does not alter responses of basal synaptic potentials. Line breaks indicate changes in time scale. (B) Analogs represent fEPSP responses (i) 5 min pre-injection, (ii) 5 min post-injection, and (iii) $24 \mathrm{~h}$ post-injection in vehicle-injected animals (left upper panel), in animals injected with a dose of $2 \mu \mathrm{g}$ propranolol (right upper panel) and in animals injected with a dose of $4 \mu \mathrm{g}$ propranolol (lower pane/). Vertical scale bar: $2 \mathrm{mV}$, horizontal scale bar: $6 \mathrm{~ms}$.

independent of NMDA receptor activation (Harris and Cotman, 1986). Application of the NMDA receptor antagonist, D-AP5 $(3.9 \mu \mathrm{g})$, revealed no significant differences in evoked responses compared to controls [ANOVA, $F_{(1,381)}=3.81 ; p=0.52 ; n=9$; Figure 2B].

To examine whether antagonism of $\beta$-adrenergic receptors affects persistent LTP that lasts for over $24 \mathrm{~h}$, we used a high frequency stimulation protocol that elicited robust LTP in vehicleinjected controls (HFS: 4 bursts of 100 pulses at $100 \mathrm{~Hz}$ ) (Figure 3). Treatment with propranolol prior to HFS resulted in LTP that was not significantly different from vehicle-injected controls [ANOVA, $F_{(1,339)}=0.24 ; p=0.62 ; n=7$ in both groups] (Figure 3).

\section{SHORT- AND LONG-TERM DEPRESSION INDUCED BY LOW FREQUENCY STIMULATION IS NOT MODULATED BY $\beta$-ADRENERGIC RECEPTORS}

To test the influence of the $\beta$-adrenergic receptor antagonist, propranolol, on electrically-induced depression, STD was induced by application of 600 pulses at $1 \mathrm{~Hz}$ (sLFS). In vehicle-injected
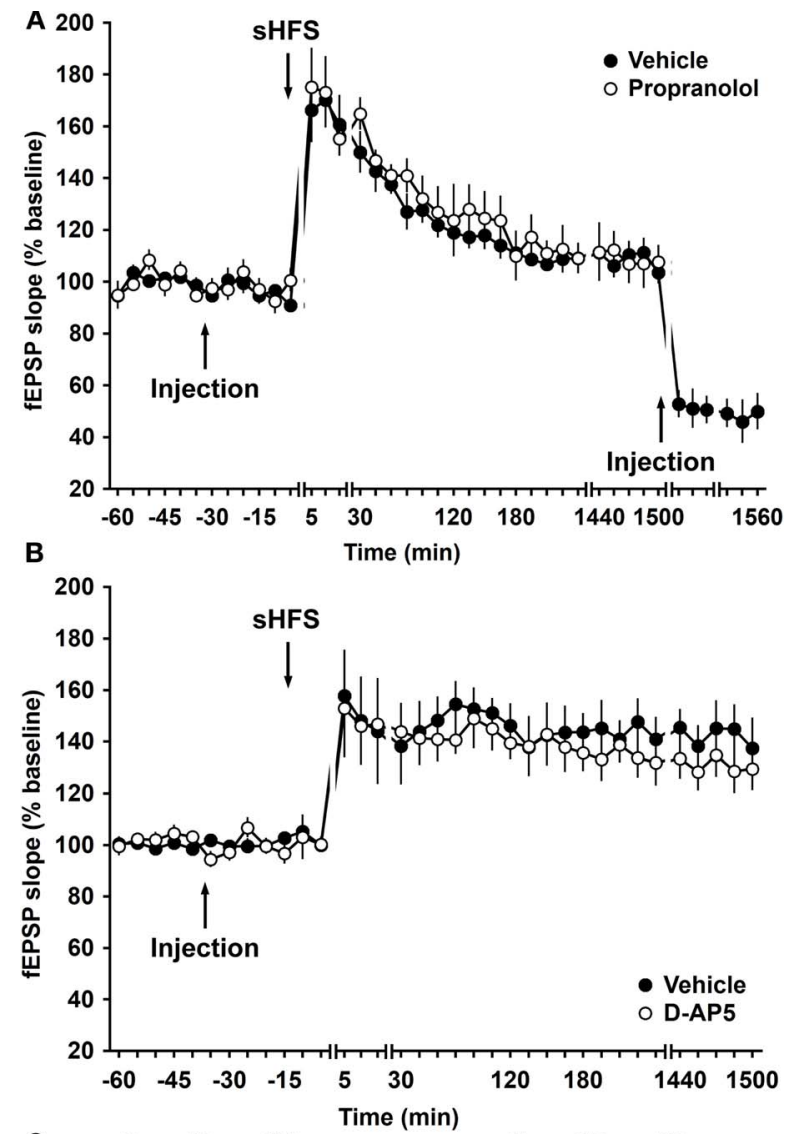

C

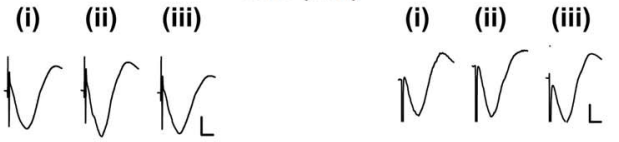

D

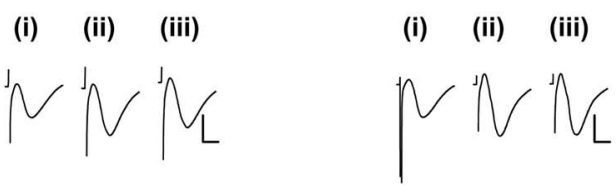

FIGURE 2 | Electrically induced STP of mossy fiber synapses is not altered by application of a $\beta$-adrenergic receptor antagonist.

(A) Application of sHFS (two trains of 100 pulses at $100 \mathrm{~Hz}$ ) results in STP. Treatment with the $\beta$-adrenergic receptor antagonist, propranolol $(2 \mu \mathrm{g})$, did not change the responses elicited. After responses had returned to baseline levels, DCG-IV was applied to confirm that responses were evoked by stimulation of mossy fibers. Line breaks indicate changes in time scale. (B) Application of the NMDA receptor antagonist, D-AP5 $(3.9 \mu \mathrm{g}) 30 \mathrm{~min}$ prior to stimulation does not alter evoked responses of LTP at mf-CA3 synapses compared to control animals. Line breaks indicate changes in time scale. (C) Analog traces were recorded (i) 5 min pre-sHFS, (ii) 5 min post-sHFS, and (iii) $24 \mathrm{~h}$ after sHFS in the presence of vehicle (left panel) or propranolol (right panel). Vertical scale bar: $2 \mathrm{mV}$, horizontal scale bar: $6 \mathrm{~ms}$. (D) Analogs of fEPSP responses (i) 5 min pre-injection, (ii) $5 \mathrm{~min}$ post-injection, and (iii) $24 \mathrm{~h}$ post-injection of animals that received D-AP5. Vertical scale bar: $2 \mathrm{mV}$, horizontal scale bar $6 \mathrm{~ms}$.

controls, sLFS elicited STD that endured for ca. $2 \mathrm{~h}(n=6$, Figure 4). Treatment with propranolol ( $2 \mu$ g, i.c.v.), prior to sLFS had no significant effect on the profile of STD (Figure 4, ANOVA, $\left.F_{(1,573)}=0.67 ; p=0.41, n=5\right)$. 


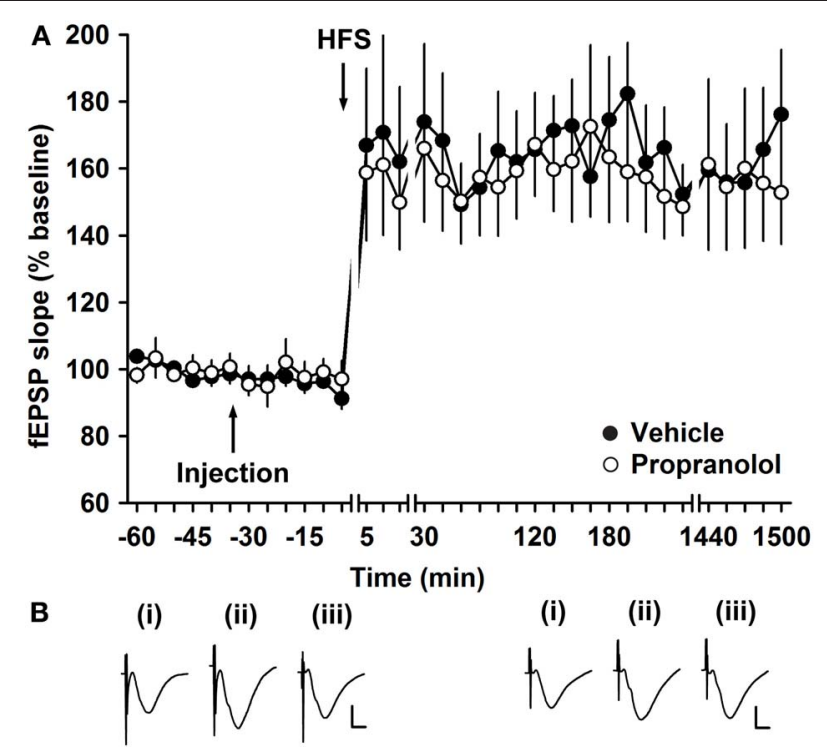

FIGURE 3 | Electrically induced LTP of mossy fiber synapses is not affected by application of a $\beta$-adrenergic receptor antagonist. (A) HFS (four trains of 100 pulses given at $100 \mathrm{~Hz}$ ) elicits LTP. Injection of the $\beta$-adrenergic receptor antagonist, propranolol $(2 \mu \mathrm{g})$, did not change the profile of the LTP elicited. Line breaks indicate changes in time scale. (B) Analog traces represent recordings taken (i) 5 min pre-LFS, (ii) 5 min post-HFS, and (iii) $24 \mathrm{~h}$ in the presence of vehicle (left pane/), or propranolol (right pane/). Vertical scale bar: $2 \mathrm{mV}$, horizontal scale bar: $6 \mathrm{~ms}$.

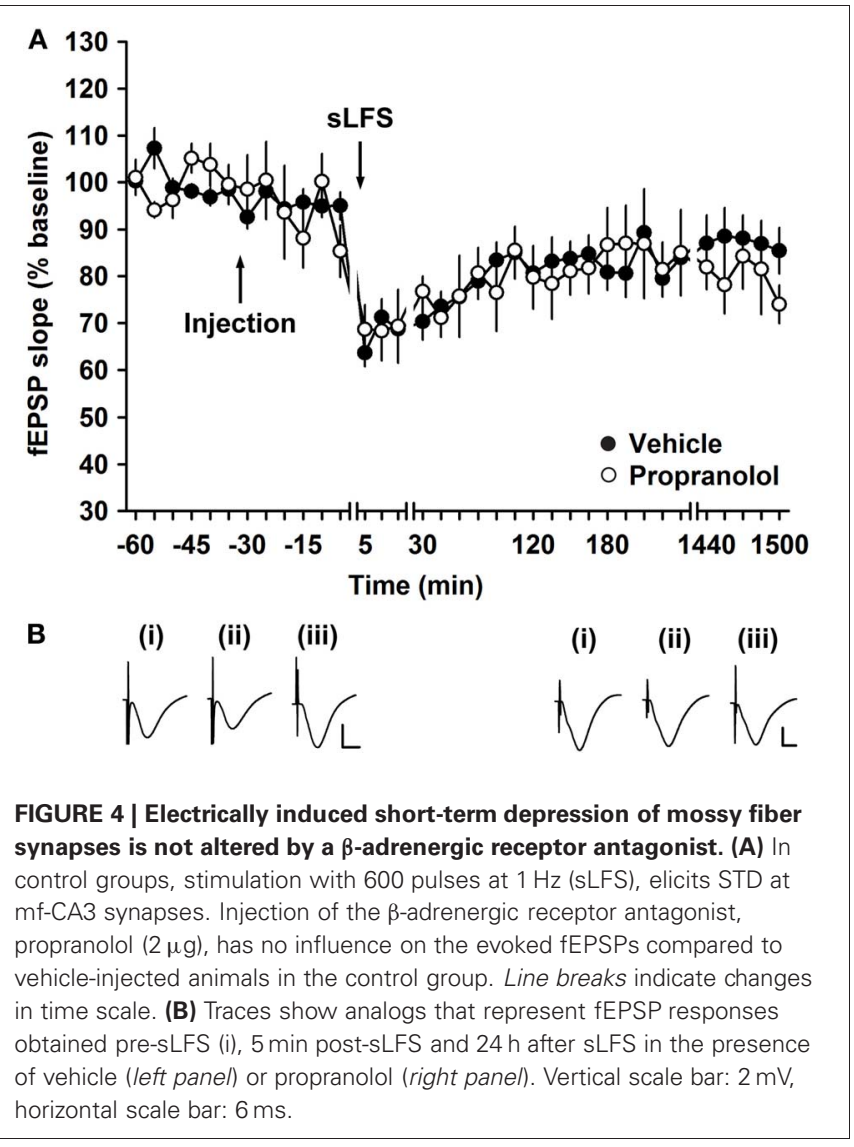

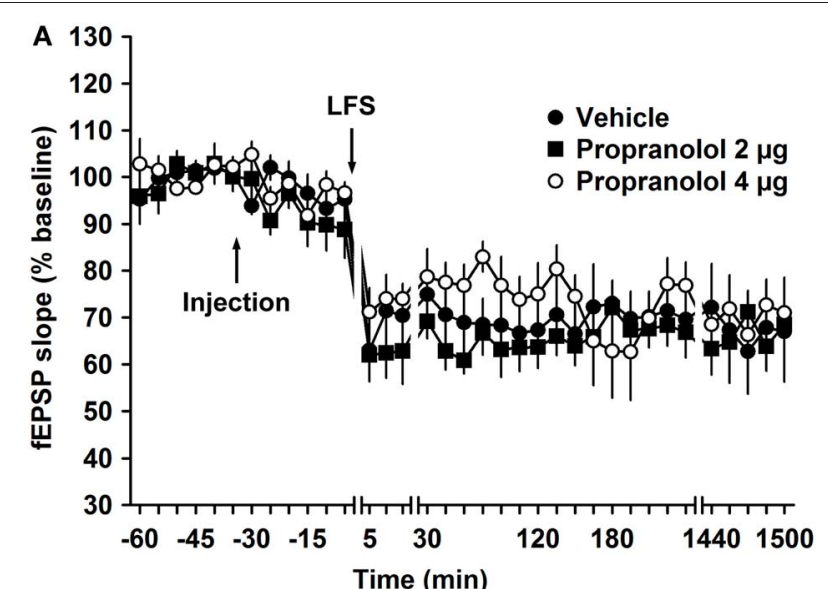

B<smiles>CCCCCC(C)CCCC</smiles>

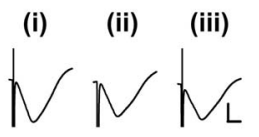

(i)

(ii)

(iii)<smiles>CCCCCC</smiles>

FIGURE 5 | $\beta$-adrenergic receptor antagonism has no effect on electrically induced long-term depression of mossy fiber synapses. (A) Injection of the $\beta$-adrenergic receptor antagonist, propranolol $(2 \mu \mathrm{g})$, has no significant effect on the profile of electrically induced LTD (elicited by low frequency stimulation, LFS, of 900 pulses at $1 \mathrm{~Hz}$ ) compared to vehicle-injection. Line breaks indicate changes in time scale. (B) Analogs represent fEPSP responses obtained (i) 5 min pre-LFS, (ii) 5 min post-LFS, and (iii) $24 \mathrm{~h}$ post-LFS in the presence of vehicle (left upper panel), in the presence of a low dose ( $2 \mu \mathrm{g}$ ) of propranolol (right upper panel) or a high dose $(4 \mu \mathrm{g})$ of propranolol (lower pane/). Vertical scale bar: $2 \mathrm{mV}$, horizontal scale bar: $6 \mathrm{~ms}$.

LFS (900 pulses at $1 \mathrm{~Hz}$ ) induced persistent LTD of mf-CA3 synapses $(>24 \mathrm{~h}$ ) in vehicle-injected controls (Figure 5, $n=9$ ). When LFS was given in the presence of propranolol $(2 \mu \mathrm{g}$, i.c.v., $n=9$ ), LTD occurred that was not significantly different from that elicited in vehicle-treated animals [ANOVA: $F_{(1,305)}=1.28$; $p=0.26$ ] (Figure 5). Increasing the amount of propranolol to $4 \mu \mathrm{g}$ showed no difference in evoked potentials compared to vehicle-injected controls [ANOVA: $F_{(1,279)}=3.35 ; p=0.07$, $n=6]$ (Figure 5).

\section{LTP FACILITATED BY NOVELTY EXPLORATION IS DEPENDENT ON $\beta$-ADRENERGIC RECEPTORS}

Exploration of an empty holeboard during application of sHFS facilitated LTP at $\mathrm{mf}$ and commissural-associational synapses (Hagena and Manahan-Vaughan, 2011) as well as at perforant path-DG and Schaffer collateral-CA1 synapses (Kemp and Manahan-Vaughan, 2004, 2008a). To elucidate if synaptic potentiation of $\mathrm{mf}$ synapses that is elicited by changes in space, depends on activation of $\beta$-adrenergic receptors, exploration of an empty holeboard after application of propranolol was examined. When sHFS was given in vehicle-injected animals in absence of a holeboard, STP occurred (Figure 6). Whereas in control animals, the combination of sHFS with novel holeboard exploration facilitates 


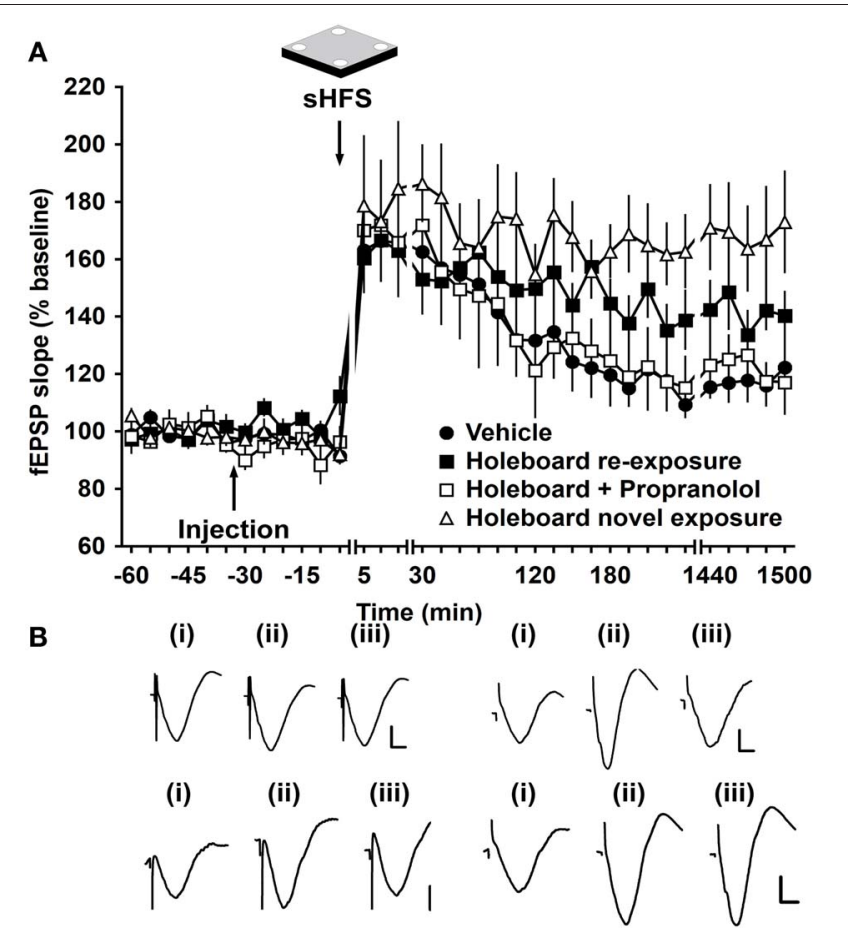

FIGURE 6 | Learning-facilitated LTP in mossy fiber synapses is regulated by $\boldsymbol{\beta}$-adrenergic receptors. (A) In control experiments, application of sHFS (two trains of 100 pulses given at $100 \mathrm{~Hz}$ ) in the absence of a novel holeboard (and in the presence of vehicle) elicits STP. The combination of SHFS with novel holeboard exploration facilitates STP into LTP. Injection of propranolol before novel exploration of an empty novel holeboard elicits STP that is similar to that seen in vehicle-injected controls. A second exposure to the holeboard (ca. one week after the original treatment with propranolol) facilitates LTP. Line breaks indicate changes in time scale. (B) Analog traces recorded (i) $5 \mathrm{~min}$ pre-sHFS, (ii) $5 \mathrm{~min}$ post-sHFS, and (iii) $24 \mathrm{~h}$ post-sHFS, from a vehicle-injected animal in the absence of holeboard (left upper pane/), from a propranolol-treated animal that was exposed to a novel empty holeboard (right upper panel), from an animal that was re-exposed to a novel empty holeboard ca. one week after the treatment with propranolol (lower left panel) and from an animal that was exposed to a novel holeboard for the first time (lower right pane/). Vertical scale bar: $2 \mathrm{mV}$, horizontal scale bar: $6 \mathrm{~ms}$.

LTP [ANOVA: $F_{(1,373)}=26.89 ; p<0.001, n=8$ ] compared to control animals in absence of a holeboard, in the presence of the $\beta$-adrenergic receptor antagonist $(2 \mu \mathrm{g}$, i.c.v., $n=6)$, no improvement of STP was seen due to holeboard exploration, suggesting that an inhibition of learning-facilitated LTP, associated with novel exploration of an empty holeboard, occurred [ANOVA, $F_{(1,519)}=0.09 ; p=0.76$ ] (Figure 6). When the animal explored the holeboard for a second time, ca. seven days after first exploration, application of sHFS, facilitated LTP [ANOVA, $F_{(1,225)}=12.64, p<0.001$ ] (Figure 6). These findings are in line with previous reports that $\beta$-adrenergic receptor antagonism prevents both learning of the spatial environment of the holeboard and learning-facilitated LTP in the CA1 region (Kemp and Manahan-Vaughan, 2008a) and as a result, the re-exposure to the holeboard is perceived as if the environment has never been explored before.
LEARNING-FACILITATED LONG-TERM DEPRESSION IS DEPENDENT ON $\beta$-ADRENERGIC RECEPTORS

Application of LFS that is sub-threshold for inducing LTD (sLFS, $1 \mathrm{~Hz}, 600$ pulses) induced STD at the mf-CA3 synapse that lasted for approximately $2 \mathrm{~h}$ before it returned to basal levels $(n=8$; Figure 7). sLFS given to vehicle-injected controls during exploration of novel, spatially arranged landmark cues led to LTD that lasted for at least $24 \mathrm{~h}(n=8$, Figure 7A). Application of the $\beta$-adrenergic receptor antagonist propranolol $(2 \mu \mathrm{g}$, i.c.v., $n=8$ ) prior to sLFS and novel landmark-exposure resulted in STD, suggesting that learning-facilitated LTD has been prevented [ANOVA, $F_{(1,469)}=18.50 ; p<0.001$ ] (Figure 7A).

The experiment was repeated ca. seven days later using the same constellation of (now familiar) cues, this time applying a vehicle injection to all groups. Here, it was observed that due to the habituation to the landmark cues (Manahan-Vaughan and Braunewell, 1999; Lemon and Manahan-Vaughan, 2006; Popkirov and Manahan-Vaughan, 2011), LTD was not facilitated in the control group upon re-exposure to the landmark cues $(n=8)$, whereas in the propranolol group $(n=5)$ the first re-exposure of the animals to the familiar cues facilitated LTD [ANOVA, $F_{(1,241)}=52.13 ; p<0.001$ ] (Figure 7B). This finding is in keeping with previous observations that propranolol blocks this type of spatial learning (Lemon et al., 2009). Thus, learningfacilitated LTD may not have occurred in the propranolol group because learning was prevented. In keeping with this hypothesis, exposing the animals formerly treated with propranolol once more (i.e., for the third time, second re-exposure) to the three spatially arranged landmarks induced STD that was significantly different from the first re-exposure after propranolol application [ANOVA, $F_{(1,172)}=39.59 ; p<0.001, n=5$ ] (Figure 7B). There was no significant difference in the responses during the first reexposure of the animals to the cues in the vehicle-treated group and the second re-exposure of the propranolol-treated group [ANOVA, $F_{(1,243)}=0.14 ; p=0.71, n=5$ ].

\section{ACTIVATION OF $\beta$-ADRENERGIC RECEPTORS FACILITATES STP INTO LTP}

To investigate whether the activation of $\beta$-adrenergic receptors can modulate STP and thus play an important role in the facilitation of LTP, we applied the $\beta$-adrenergic receptor agonist isoproterenol. In control animals, sHFS leads to STP that returned to baseline levels after ca. $180 \mathrm{~min}$. Application of isoproterenol $(20 \mu \mathrm{g}) 30 \mathrm{~min}$ before sHFS, facilitated STP into LTP that lasted over $24 \mathrm{~h}$ [ANOVA, $F_{(1,202)}=52.845 ; p<0.001$, $n=6]$ (Figure 8).

\section{DISCUSSION}

This study offers two main observations: learning-facilitated plasticity at $\mathrm{mf}$ synapses is dependent upon activation of $\beta$-adrenergic receptors, whereas synaptic plasticity that is solely induced by electrical stimulation of $\mathrm{mf}$ afferents, is not. This suggests that plasticity associated by learning behavior is highly sensitive to regulation by $\beta$-adrenergic receptors and that this kind of plasticity may be mechanistically different from the standard experimental form of synaptic plasticity that is induced by electrical stimulation. This is supported by our observations that raising the dose 


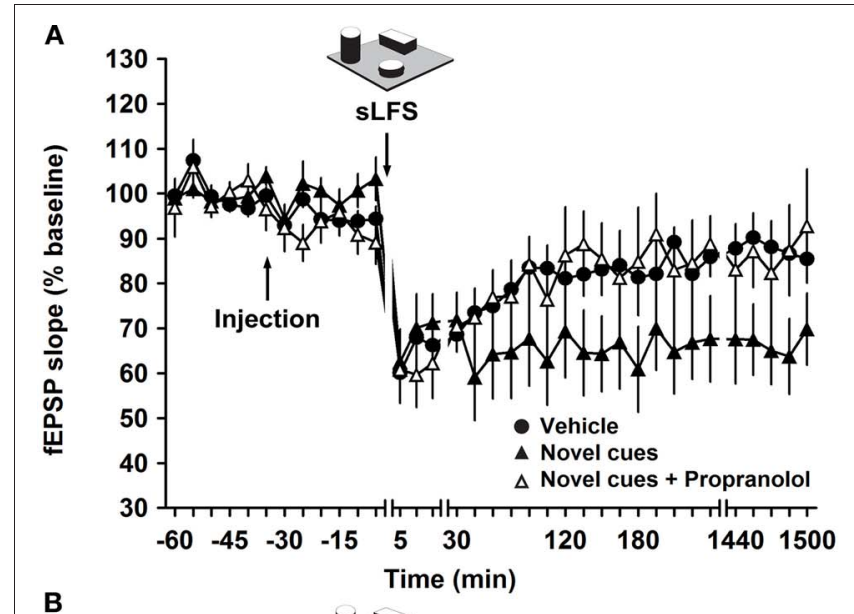

B

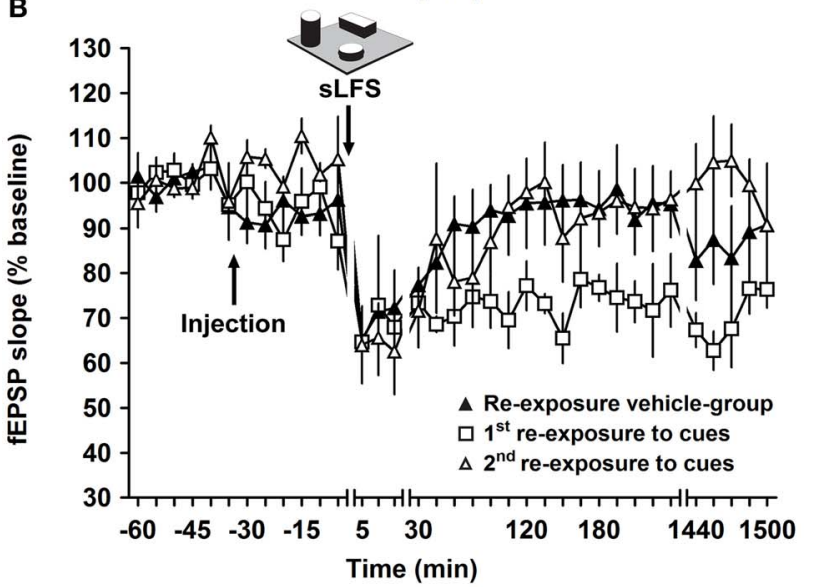

C

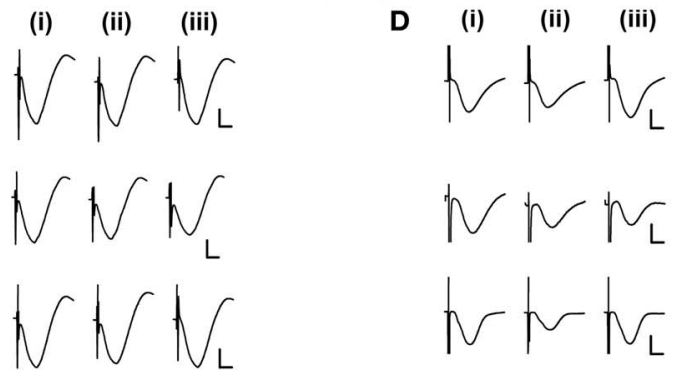

FIGURE 7 | Learning-facilitated LTD depends on the activation of $\beta$-adrenergic receptors at mossy fiber-CA3 synapses. (A) Application of $1 \mathrm{~Hz}$ stimulation (sLFS: 600 pulses) without objects induces STD at mossy fiber-CA3 synapses. SLFS given to vehicle-treated animals during exploration of landmark cues led to LTD that lasted for at least $24 \mathrm{~h}$. In the presence of propranolol, LTD expression is impaired during exploration of three novel cues. LTD is facilitated when the animal explores the same three cues for the second time. Changes in time scale are indicated by line breaks. (B) Re-exposure of vehicle-treated animals to the landmark cues (ca. seven days after first exposure) results in STD, whereas re-exposure to the landmark cues, of the animals that were injected with propranolol (ca. one week previously, during the "novel exposure" experiment), facilitates LTD. A further (second) re-exposure of these animals to the landmark objects (ca. one week after the first re-exposure) results in STD. Changes in time scale are indicated by line breaks. (C) Analogs recorded during experiments shown in (A), 5 min pre-sLFS (i), 5 min post-sLFS (ii) and $24 \mathrm{~h}$ post-sLFS (iii). Top row represents fEPSP responses obtained during application of SLFS in vehicle-treated animals in the absence of novel landmarks, middle row represent responses elicited in animals that

(Continued)

\section{FIGURE 7 | Continued}

underwent exploration of novel landmarks, and bottom row shows fEPSPs evoked in propranolol-treated animals that underwent exploration of novel landmarks. Vertical scale bar: $2 \mathrm{mV}$, horizontal scale bar: $6 \mathrm{msec}$. (D) Analog traces recorded during experiments shown in (B), 5 min pre-sLFS (i), $5 \mathrm{~min}$ post-sLFS (ii), and $24 \mathrm{~h}$ post-sLFS (iii). The top row represent analogs from a vehicle-treated animal that underwent a second exposure to the landmarks, middle row depict fEPSP responses from a first re-exposure experiment (in an animal formerly treated with propranolol) and the bottom row represent responses of fEPSPs recorded during the second re-exposure experiment (in an animal formerly treated with propranolol). Vertical scale bar: $2 \mathrm{mV}$, horizontal scale bar: $6 \mathrm{~ms}$.

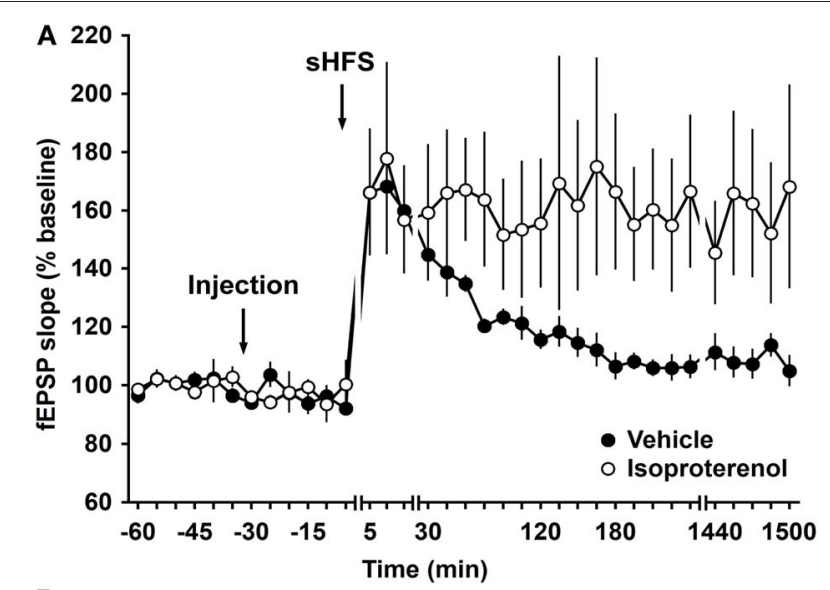

B

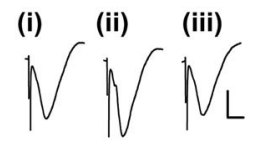<smiles>CC(=O)C(C)=C(C)C=C(C)C</smiles>

FIGURE 8 | Activation of $\beta$-adrenergic receptors facilitates STP into LTP. (A) Application of sHFS (two trains of 100 pulses at $100 \mathrm{~Hz}$ ) elicits STP in vehicle-injected animals. Injection of the $\beta$-adrenergic receptor agonist isoproterenol $(20 \mu \mathrm{g}) 30 \mathrm{~min}$ prior to stimulation significantly facilitates STP into LTP. Line breaks indicate change of time-scale. (B) Analog traces recorded from an animal during the control experiment (i) 5 min pre-sHFS, (ii) $5 \mathrm{~min}$ post-sHFS, and (iii) $24 \mathrm{~h}$ post-sHFS. Vertical scale bar: $2 \mathrm{mV}$, horizontal scale bar: $6 \mathrm{~ms}$.

of the $\beta$-adrenergic receptor antagonist did not result in an inhibition of electrically induced plasticity. These findings are in line with observations from other hippocampal synapses (Kemp and Manahan-Vaughan, 2008a) but are all the more striking given the very clear mechanistic differences underlying synaptic plasticity at mf-CA3 synapses in comparison to the perforant pathdentate gyrus and the Schaffer collateral-CA1 synapse (Harris et al., 1984; Zalutsky and Nicoll, 1990; Johnston et al., 1992; Bliss and Collingridge, 1993; Manahan-Vaughan and Reymann, 1996; Maccaferri et al., 1998; Mellor and Nicoll, 2001; Nicoll and Schmitz, 2005).

Activation of the locus coeruleus by novelty leads to release of noradrenalin in the hippocampus and subsequent activation of $\beta$-adrenergic receptors (Sara et al., 1994; Kitchigina et al., 1997; Lemon and Manahan-Vaughan, 2006). This response presumably 
serves to increase the salience of novel sensory information and enhanced hippocampal encoding (Lemon and ManahanVaughan, 2006). The main source of noradrenalin in the brain is the locus coeruleus (Sara et al., 1994; Kitchigina et al., 1997) which, when activated for example by novel spatial stimuli, enhances the release of noradrenalin and also depresses synaptic responses at Schaffer collateral-CA1 synapses inducing NMDA receptor and $\beta$-adrenergic receptor dependent LTD (Lemon et al., 2009), that has been implicated in encoding of novel spatial information (Manahan-Vaughan and Braunewell, 1999; Li et al., 2003; Kemp and Manahan-Vaughan, 2004). This effect does not appear to be subregion-specific in the hippocampus, as learning-facilitated plasticity at both the mf-CA3 synapse and the Schaffer collateral-CA1 synapse (Kemp and Manahan-Vaughan, $2008 \mathrm{~b})$ are regulated by $\beta$-adrenergic receptors. Furthermore, the locus coeruleus extends noradrenergic projections to the stratum lucidum of area CA3 (Loy et al., 1980) where $\beta$-adrenergic receptors have been found (Oleskevich et al., 1989), supporting the role of $\beta$-adrenergic receptors in synaptic plasticity in area CA3. $\beta$-adrenergic receptors appear to regulate synaptic plasticity by lowering the thresholds for the induction (Katsuki et al., 1997; Lemon et al., 2009) and supporting the expression of LTD and LTP (Thomas et al., 1996; Katsuki et al., 1997; Gelinas and Nguyen, 2005; Gelinas et al., 2007). This generalized property may reflect a directed change of responsiveness of the hippocampus in response to increase informational salience (mediated by locus coeruleus activity) that in turn contributes to facilitated expression of persistent synaptic plasticity and, presumably persistent memory. Activation of $\beta$-adrenergic receptors by injecting isoproterenol before application of sHFS facilitated LTP and simulated the effect of learning-facilitated plasticity. This suggests that release of noradrenaline that is triggered by novel spatial experience is a critical component for the processing of novel information by means of synaptic plasticity in the hippocampus.

Although synaptic plasticity at mf-CA3 synapses is mechanistically different from plasticity at Schaffer collateral-CA1 or perforant path-dentate gyrus synapses, common properties are also evident in terms of how hippocampal plasticity within the trisynaptic circuit is facilitated by learning events (Kemp and Manahan-Vaughan, 2007, 2008a; Hagena and ManahanVaughan, 2011). In particular both mf-CA3 and perforant pathdentate gyrus synapses exhibit a facilitation of LTD when patterned stimulation (that is sub-threshold for induction of lasting plasticity) is coupled with the novel exploration of large landmark features of an environment. Furthermore, selected synapses within all stages of the trisynaptic circuit respond with facilitated LTP to exposure to novel spatial environments (Kemp and Manahan-Vaughan, 2007, 2008a; Hagena and ManahanVaughan, 2011). This suggests a partnership of sorts between the dentate gyrus and CA3 region in terms of information processing, that may relate to the postulated role of the dentate gyrus in pattern separation (Kesner et al., 2004) and of the mf-CA3 synapse in pattern separation and completion, resulting in an rapid encoding of new information (Nakazawa et al., 2003; Lee et al., 2004).
It is striking, that $\beta$-adrenergic receptors are required for learning-facilitated plasticity but not for plasticity that was induced solely through patterned electrical stimulation. Both of these observations have also been reported for Schaffer collateral-CA1 synapses in freely behaving adult rats (Kemp and Manahan-Vaughan, 2008b; Lemon et al., 2009). Interestingly, it has been reported that antagonism of $\beta$-adrenergic receptors impairs electrically-induced LTP in the rat dentate gyrus in vivo (Straube and Frey, 2003; Straube et al., 2003a), suggesting that sub-regional effects of $\beta$-adrenergic receptors on hippocampal plasticity in vivo may occur. In contrast to the observation that pharmacological blockade of $\beta$-adrenergic receptors does not affect electrically-induced LTP at mf-CA3 and Schaffer collateralCA1 synapses in vivo, in rodent hippocampal slices, plasticity that is solely induced by electrical stimulation is sensitive to pharmacological modulation of $\beta$-adrenergic receptors, both in Schaffer collateral- CA1 (Gelinas and Nguyen, 2005) and mf-CA3 synapses (Hopkins and Johnston, 1988). Conversely, in mouse hippocampal slices, an absence of effect of propranolol application on the expression of LTP in CA1 has been reported (Schimanski et al., 2007).

In our study, ligands were applied via the lateral cerebral ventricle. This means that effects on other hippocampal subregions or on structures neighboring the lateral ventricle cannot be excluded. In fact, we have also seen that antagonism of $\beta$-adrenergic receptors also affects synaptic plasticity in the CA1 region and dentate gyrus (Kemp and Manahan-Vaughan, 2008b; Lemon et al., 2009). Furthermore, $\beta$-adrenergic receptors have been found in various regions of the rat brain, such as the cerebral cortex, hippocampus, the cerebellum, the thalamus, or the amygdala (Fuxe, 1965; Minneman et al., 1979). Thus, indirect effects may play a role in the changes in responses we observe here. Nonetheless, the finding that the $\mathrm{mf}$ synapse is so potently affected supports the possibility that the $\beta$-adrenergic receptor elicits a strong regulatory control of information processing within this hippocampal substructure.

Where does the difference lie between learning-facilitated LTP and LTP that is elicited by sole electrical stimulation of afferent fibers? Activation of $\beta$-adrenergic receptors results in an activation of the cAMP second messenger pathway. This pathway is important for the induction of LTP at mf-CA3 synapses in vitro (Huang et al., 1994; Weisskopf et al., 1994). In line with this, in CA1 synapses, activation of $\beta$-adrenergic receptors primes for induction of LTP (Gelinas and Nguyen, 2005; Gelinas et al., 2007). Under the conditions of learning-facilitation of LTP, weak potentiation is facilitated into strong and robust LTP by a novel learning experience. In general, novel information or exploration, leads to the activation of the locus coeruleus and the subsequent activation of $\beta$-adrenergic receptors (Sara et al., 1995). This in turn will support cAMP-dependent processes underlying LTP and may enable strengthening of weak plasticity. In line with this, it has been reported that $\beta$-adrenergic receptor activation enhances CA3 network activity by increasing CA3 burst activity (Jurgens et al., 2005) and facilitates the induction of LTP and sharp-wave ripples (U1 Haq et al., 2011). Under conditions where LTP is induced solely by electrical stimulation of 
afferent fibers, the LTP that is induced is already "strong." This induction of very potent and persistent LTP may thus circumvent the need for support through the noradrenergic system and enable cAMP-dependent pathways to be recruited by the stronger activation of glutamatergic receptors or by other neuromodulatory systems.

\section{CONCLUSION}

Whereas LTP at $\mathrm{mf}$ synapses is facilitated by exploration of a new environment, LTD is facilitated when spatial landmarks are included in a spatial environment. These differences may underlie the piecing together of different components of spatial representation such that a composite and comprehensive spatial memory is enabled. Both forms of plasticity are regulated by $\beta$-adrenergic receptors, whereas synaptic plasticity that is induced solely by electrical stimulation of $\mathrm{mf}$ synapses does not require activation of these receptors. This suggests that forms of synaptic plasticity that are induced experimentally by relatively strong synaptic stimulation may be relatively impervious to neuromodulators, because the threshold for inducing plasticity has already been reached. More fragile forms of synaptic plasticity that are enabled when weak afferent stimulation is coupled with a spatial learning experience appear more sensitive to neuromodulation by $\beta$-adrenergic receptors. This finding is in line with data obtained in previous studies, suggesting that the noradrenergic system, mediated by activation of $\beta$-adrenergic receptors in the hippocampus, plays a prominent role in increasing arousal and information processing during novel learning conditions (Sara et al., 1994; Vankov et al., 1995; Lemon and Manahan-Vaughan, 2006; Kemp and Manahan-Vaughan, 2008b).

The findings of this study support the assumption that learning-facilitated plasticity at $\mathrm{mf}$ synapses depends on the activation of the noradrenergic system. Our data also support that the processing of novel spatial information at mf-CA3 synapses is mediated by $\beta$-adrenergic receptors, which presumably transiently strengthen synaptic connections to promote the processing of salient information in favor of less relevant information. Furthermore, these findings indicate that the noradrenergic system may serve to mediate coherence in the processing of salient information across hippocampal synapses, and that the mf-CA3 synapse, despite mechanistic differences in synaptic plasticity compared to the other synapses of the trisynaptic circuit, may under these conditions respond unisono with other selected hippocampal synapses in the generation of a memory engram through synaptic plasticity.

\section{ACKNOWLEDGMENTS}

This work is support by a grant from the German research foundation (DFG) to Denise Manahan-Vaughan. We thank Jens Klausnitzer for technical assistance and Nadine Gomell for animal care.

\section{REFERENCES}

Bear, M. F., and Abraham, W. C. (1996). Long-term depression in hippocampus. Annu. Rev. Neurosci. 19, 437-462.

Bear, M. F., and Malenka, R. C. (1994). Synaptic plasticity: LTP and LTD. Curr. Opin. Neurobiol. 4, 389-399.

Bliss, T. V., and Collingridge, G. L. (1993). A synaptic model of memory: long-term potentiation in the hippocampus. Nature 361, 31-39.

Blum, K. I., and Abbott, L. F. (1996). A model of spatial map formation in the hippocampus of the rat. Neural Comp. 8, 85-93.

Bock, P. (1989). Romeis, Mikroskopische Technik. München: Urban und Schwarzenberg.

Bortolotto, Z., Lauri, S., Isaac, J., and Collingridge, G. (2003). Kainate receptors and the induction of mossy fibre long-term potentiation. Philos. Trans. R. Soc. Lond. B Biol. Sci. 358, 657-666.

Bouret, S., and Sara, S. J. (2005). Network reset: a simplified overarching theory of locus coeruleus noradrenaline function. Trends Neurosci. 28, 574-582.
Contractor, A., Swanson, G., and Heinemann, S. F. (2001). Kainate receptors are involved in shortand long-term plasticity at mossy fiber synapses in the hippocampus. Neuron 29, 209-216.

Delini-Stula, A., Mogilnicka, E., Hunn, C., and Dooley, D. J. (1984). Novelty-oriented behavior in the rat after selective damage of locus coeruleus projections by DSP-4, a new noradrenergic neurotoxin. Pharmacol. Biochem. Behav. 20, 613-618.

Devauges, V., and Sara, S. J. (1991). Memory retrieval enhancement by locus coeruleus stimulation: evidence for mediation by betareceptors. Behav. Brain Res. 43, 93-97.

Fuxe, K. (1965). Evidence for the existence of monoamine neurons in the central nervous system. iv. Distribution of monoamine nerve terminals in the central nervous system. Acta Physiol. Scand. Suppl. 247, 37.

Gelinas, J. N., Banko, J. L., Hou, L., Sonenberg, N., Weeber, E. J., Klann, E., and Nguyen, P. (2007). ERK and mTOR signaling couple beta-adrenergic receptors to translation initiation machinery to gate induction of protein synthesis-dependent long-term potentiation. J. Biol. Chem. 282, 27527-27535.

Gelinas, J. N., and Nguyen, P. (2005). Beta-adrenergic receptor activation facilitates induction of a protein synthesis-dependent late phase of long-term potentiation. J. Neurosci. 25, 3294-3303.

Goussakov, I. V., Fink, K., Elger, C. E., and Beck, H. (2000) Metaplasticity of mossy fiber synaptic transmission involves altered release probability. J. Neurosci. 20, 3434-3441.

Hagena, H., and Manahan-Vaughan, D. (2010). Frequency facilitation at mossy fiber-CA3 synapses of freely behaving rats contributes to the induction of persistent LTD via an adenosine-A1 receptor-regulated mechanism. Cereb. Cortex 20, 1121-1130.

Hagena, H., and Manahan-Vaughan, D. (2011). Learning-facilitated synaptic plasticity at CA3 mossy fiber and commissural-associational synapses reveals different roles in information processing. Cereb. Cortex 21, 2442-2449.
Harris, E. W., and Cotman, C. W. (1986). Long-term potentiation of guinea pig mossy fiber responses is not blocked by N-methyl Daspartate antagonists. Neurosci. Lett. $70,132-137$.

Harris, E. W., Ganong, A. H., and Cotman, C. W. (1984). Long-term potentiation in the hippocampus involves activation of N-methyl-Daspartate receptors. Brain Res. 323, 132-137.

Hopkins, W. F., and Johnston, D. (1988). Noradrenergic enhancement of long-term potentiation at mossy fiber synapses in the hippocampus. J. Neurophysiol. 59, 667-687.

Huang, Y. Y., Li, X. C., and Kandel, E. R. (1994). cAMP contributes to mossy fiber LTP by initiating both a covalently mediated early phase and macromolecular synthesis-dependent late phase. Cell 79, 69-79.

Ikegaya, Y., Nakanishi, K., Saito, H., and Abe, K. (1997). Amygdala betanoradrenergic influence on hippocampal long-term potentiation in vivo. Neuroreport 8, 3143-3146.

Jaffe, D., and Johnston, D. (1990). Induction of long-term potentiation 
at hippocampal mossy-fiber synapses follows a Hebbian rule. J. Neurophysiol. 64, 948-960.

Johnston, D., Williams, S., Jaffe, D., and Gray, R. (1992). NMDAreceptor-independent long-term potentiation. Annu. Rev. Physiol. 54, 489-505.

Jurgens, C. W., Rau, K. E., Knudson, C. A., King, J. D., Carr, P. A., Porter, J. E., and Doze, V. A. (2005). Betal adrenergic receptor-mediated enhancement of hippocampal CA3 network activity. J. Pharmacol. Exp. Ther. 314, 552-560.

Kamiya, H., and Ozawa, S. (1998). Kainate receptor-mediated inhibition of presynaptic $\mathrm{Ca}^{2+}$ influx and EPSP in area CA1 of the rat hippocampus. J. Physiol. 509, 833-845.

Katsuki, H., Izumi, Y., and Zorumski, C. F. (1997). Noradrenergic regulation of synaptic plasticity in the hippocampal CA1 region. J. Neurophysiol. 77, 3013-3020.

Kemp, A., and Manahan-Vaughan, D. (2004). Hippocampal longterm depression and long-term potentiation encode different aspects of novelty acquisition. Proc. Natl. Acad. Sci. U.S.A. 101, 8192-8197.

Kemp, A., and Manahan-Vaughan, D. (2007). Hippocampal long-term depression: master or minion in declarative memory processes? Trends Neurosci. 30, 111-118.

Kemp, A., and Manahan-Vaughan, D. (2008a). The hippocampal CA1 region and dentate gyrus differentiate between environmental and spatial feature encoding through longterm depression. Cereb. Cortex 18, 968-977.

Kemp, A., and Manahan-Vaughan, D. (2008b). $\beta$-adrenoreceptors comprise a critical element in learning-facilitated long-term plasticity. Cereb. Cortex 18, 1324-1326.

Kesner, R. P., Lee, I., and Gilbert, P. (2004). A behavioral assessment of hippocampal function based on a subregional analysis. Rev. Neurosci. $15,333-351$.

Kitchigina, V., Vankov, A., Harley, C., and Sara, S. J. (1997). Noveltyelicited, noradrenaline-dependent enhancement of excitability in the dentate gyrus. Eur. J. Neurosci. 9, 41-47.

Klausnitzer, J., and Manahan-Vaughan, D. (2008). Frequency facilitation at mossy fiber-CA3 synapses of freely behaving rats is regulated by adenosine A1 receptors. J. Neurosci. $28,4836-4840$.

Lee, I., Rao, G., and Knierim, J. J. (2004). A double dissociation between hippocampal subfields: differential time course of $\mathrm{CA} 3$ and CA1 place cells for processing changed environments. Neuron 42 , 803-815.

Lemon, N., Aydin-Abidin, S., Funke, K., and Manahan-Vaughan, D. (2009). Locus coeruleus activation facilitates memory encoding and induces hippocampal LTD that depends on $\beta$-adrenergic receptor activation. Cereb. Cortex 19, 2827-2837.

Lemon, N., and Manahan-Vaughan, D. (2006). Dopamine D1/D5 receptors gate the acquisition of novel information through hippocampal long-term potentiation and longterm depression. J. Neurosci. 26 7723-7729.

Li, S., Cullen, W. K., Anwyl, R., and Rowan, M. J. (2003). Dopaminedependent facilitation of LTP induction in hippocampal CAl by exposure to spatial novelty. Nat. Neurosci. 6, 3803-3815.

Loy, R., Koziell, D. A., Lindsey, J. D., and Moore, R. Y. (1980). Noradrenergic innervation of the adult rat hippocampal formation. J. Comp. Neurol. 189, 699-710.

Maccaferri, G., Toth, K., and McBain, C. J. (1998). Targetspecific expression of presynaptic mossy fiber plasticity. Science 279, 1368-1370.

Manahan-Vaughan, D. (1997). Group 1 and 2 metabotropic glutamate receptors play differential roles in hippocampal long-term depression and long-term potentiation in freely moving rats. J. Neurosci. 17, 3303-3311.

Manahan-Vaughan, D., Behnisch, G., Vieweg, S., Reymann, K. G., and Behnisch, T. (1998). Semiautomated analysis of NMDA-mediated toxicity in digitised colour images from rat hippocampus. J. Neurosci. Methods 82, 85-95.

Manahan-Vaughan, D., and Braunewell, K. H. (1999). Novelty acquisition is associated with induction of hippocampal long-term depression. Proc. Natl. Acad. Sci. U.S.A. 96, 8739-8744.

Manahan-Vaughan, D., and Reymann, K. G. (1996). Metabotropic glutamate receptor subtype agonists facilitate long-term potentiation within a distinct time window in the dentate gyrus in vivo. Neuroscience 74, 723-731.
McNaughton, B., and Morris, R (1987). Hippocampal synaptic enhancement and information storage within a distributed memory system. Trends Neurosci. 10, 408-415.

Mellor, J., and Nicoll, R. A. (2001). Hippocampal mossy fiber LTP is independent of postsynaptic calcium. Nat. Neurosci. 4, 125-126.

Minneman, K. P., Hegstrand, L. R., and Molinoff, P. B. (1979). Simultaneous determination of beta- 1 and beta- 2 adrenergic receptors in tissues containing both receptor subtypes. $\mathrm{Mol}$. Pharmacol. 16, 34-46.

Murchison, C. F., Zhang, X. Y., Zhang, W. P., Ouyang, M., Lee, A., and Thomas, S. A. (2004). A distinct role for norepinephrine in memory retrieval. Cell 117, 131-143.

Nakazawa, K., Sun, L. D., Quirk, M. C., Rondi-Reig, L., Wilson, M., and Tonegawa, S. (2003). Hippocampal CA3 NMDA receptors are crucial for memory acquisition of one-time experience. Neuron 38 305-315.

Nicoll, R., and Schmitz, D. (2005). Synaptic plasticity at hippocampal mossy fibre synapses. Nat. Rev. Neurosci. 6, 863-876.

Oleskevich, S., Descarries, L., and Lacaille, J. C. (1989). Quantified distribution of the noradrenaline innervation in the hippocampus of adult rat. J. Neurosci. 9, 3803-3815.

O'Reilly, R. C., and McClelland, J. L. (1994). Hippocampal conjunctive encoding, storage, and recall: avoiding a trade-off. Hippocampus 4, 661-682.

Popkirov, S. G., and ManahanVaughan, D. (2011). Involvement of metabotropic glutamate receptor mGluR5 in learning facilitatedplasticity at CA1 synapses. Cereb. Cortex 21, 501-519.

Roullet, P., and Sara, S. (1998). Consolidation of memory after its reactivation: involvement of beta noradrenergic receptors in the late phase. Neural Plast. 6, 63-68.

Sara, S. J., Dyon-Laurent, C., and Herve, A. (1995). Novelty seeking behavior in the rat is dependent upon the integrity of the noradrenergic system. Brain Res. Cogn. Brain Res. 2, 181-187.

Sara, S. J., Vankov, A., and Herve, A. (1994). Locus coeruleus-evoked responses in behaving rats: a clue to the role of noradrenaline in memory. Brain Res. Bull. 35, 457-465.

Schimanski, L. A., Ali, D. W., Baker, G. B., and Nguyen, P. (2007). Impaired hippocampal LTP in inbred mouse strains can be rescued by betaadrenergic receptor activation. Eur. J. Neurosci. 25, 1589-1598.

Straube, T., and Frey, J. U. (2003). Involvement of beta-adrenergic receptors in protein synthesisdependent late long-term potentiation (LTP) in the dentate gyrus of freely moving rats: the critical role of the LTP induction strength. Neuroscience 119, 473-479.

Straube, T., Korz, V., Balschun, D., and Frey, J. U. (2003a). Requirement of beta-adrenergic receptor activation and protein synthesis for LTPreinforcement by novelty in rat dentate gyrus. J. Physiol. 552, 953-960.

Swanson-Park, J. L., Coussens, C. M., Mason-Parker, S. E., Raymond, C. R., Hargreaves, E. L., Dragunow, M., Cohen, A. S., and Abraham, W. C. (1999). A double dissociation within the hippocampus of dopamine D1/D5 receptor and beta-adrenergic receptor contributions to the persistence of longterm potentiation. Neuroscience 92 485-497.

Tenorio, G., Connor, S. A., Guévremont, D., Abraham, W. C., Williams, J., O'Dell, T. J., and Nguyen, P. V. (2010). "Silent" priming of translation-dependent LTP by $\beta$-adrenergic receptors involves phosphorylation and recruitment of AMPA receptors. Learn. Mem. 17, 627-638.

Thomas, M. J., Moody, T. D., Makhinson, M., and O'Dell, T. J. (1996). Activity-dependent beta-adrenergic modulation of low frequency stimulation induced LTP in the hippocampal CA1 region. Neuron 17, 475-482.

Treves, A., and Rolls, E. T. (1992). Computational constraints suggest the need for two distinct input systems to the hippocampal CA3 network. Hippocampus 2, 189-199.

Ul Haq, R., Liotta, A., Kovacs, R., Rösler, A., Jarosch, M. J., Heinemann, U., and Behrens, C. J. (2011). Adrenergic modulation of sharp wave-ripple activity in rat hippocampal slices. Hippocampus 22, 516-533.

Vankov, A., Herve-Minvielle, A., and Sara, S. J. (1995). Response to novelty and its rapid habituation in locus coeruleus neurons of the freely exploring rat. Eur. J. Neurosci. 7 , 1180-1187.

Weisskopf, M. G., Castillo, P. E., Zalutsky, R. A., and Nicoll, R. A. (1994). Mediation of hippocampal 
mossy fiber long-term potentiation by cyclic AMP. Science 265, 1878-1882.

Winder, D. G., Martin, K. C., Muzzio, I. A., Rohrer, D., Chruscinski, A., Kobilka, B., and Kandel, E. R. (1999). ERK plays a regulatory role in induction of LTP by theta frequency stimulation and its modulation by beta-adrenergic receptors. Neuron 24, 715-726.

Yeckel, M. F., Kapur, A., and Johnston, D. (1999). Multiple forms of
LTP in hippocampal CA3 neurons use a common postsynaptic mechanism. Nat. Neurosci. 2, 625-633.

Zalutsky, R. A., and Nicoll, R. A. (1990). Comparison of two forms of long-term potentiation in single hippocampal neurons. Science 248 , 1619-1624.

Conflict of Interest Statement: The authors declare that the research was conducted in the absence of any commercial or financial relationships that could be construed as a potential conflict of interest.

Received: 16 December 2011; paper pending published: 24 January 2012; accepted: 04 May 2012; published online: 23 May 2012.

Citation: Hagena $H$ and ManahanVaughan D (2012) Learning-facilitated long-term depression and long-term potentiation at mossy fiber-CA3 synapses requires activation of $\beta$-adrenergic receptors. Front. Integr. Neurosci. 6:23. doi: 10.3389/fnint 2012.00023

Copyright (c) 2012 Hagena and Manahan-Vaughan. This is an openaccess article distributed under the terms of the Creative Commons Attribution Non Commercial License, which permits non-commercial use, distribution, and reproduction in other forums, provided the original authors and source are credited. 